\title{
La "actuación injustificadamente errónea" y la "actuación arbitraria" como fuentes de responsabilidad del Estado en el sistema chileno de persecución penal
}

\section{The "unjustified erroneous action" and "arbitrary action" as sources of State liability in the Chilean criminal prosecution system}

\author{
Roberto NAVARro-Dolmestch ${ }^{1}$
}

\begin{abstract}
RESUMEN
Este artículo analiza el desarrollo jurisprudencial de los elementos generadores de responsabilidad del Estado por actuaciones judiciales y del Ministerio Público arbitrarias o injustificadamente erróneas. Se destaca que ellas han sido entendidas como actuaciones personales del juez o del fiscal y que, para su configuración, se requiere una actuación dolosa o culposa, es decir, elementos de naturaleza esencialmente fáctica. Se sostiene que esta forma de interpretar la responsabilidad, aquí denominada institucional, limita su rol garantista. En consecuencia, se propone una reinterpretación de sus elementos generadores, desvinculándolos de elementos fácticos y confiriéndoles un sentido normativo. Así, se sostiene que las normas actualmente vigentes sobre la responsabilidad institucional pueden ser interpretadas en el sentido de que ella surge ante un incumplimiento de un deber.
\end{abstract}

Palabras clave: actuación arbitraria, actuación errónea, responsabilidad del Ministerio Público, indemnización.

\begin{abstract}
This paper analyzes the jurisprudential development of the elements to impose liability to the State by judges and prosecutor office's attorneys, unjustifiably erroneous or arbitrary actions. It should be noted that they have been understood as personal actions of the judge or prosecutor and that, for their configuration, a malicious or negligent action is required, that is, elements of an essentially factual nature. It is argued that this way of interpreting liability, here called institutional, limits its guaranteeing role. Consequently, a reinterpretation of its generative elements is proposed, dissociating them from factual elements and giving them a normative meaning. Thus, it is argued that the current rules about institutional liability can be interpreted in the sense that it arises from a breach of duty.
\end{abstract}

Keywords: arbitrary action, erroneous action, responsibility of the Public Ministry, compensation.

Abogado. Magíster en Derecho Penal por la Universidad de Talca y Pompeu Fabra. Profesor asistente de Derecho Penal, Universidad Autónoma de Chile. Dirección postal: Cinco Poniente 1670, Talca. Correo electrónico: roberto.navarro@uautonoma.cl 


\section{Introducción ${ }^{2}$}

El sistema de persecución penal chileno ${ }^{3}$ contempla dos regímenes específicos de responsabilidad del Estado previstos, en particular, dentro del sistema de persecución penal, conforme con los cuales el Estado debe indemnizar los dańos ocasionados por actuaciones injustificadamente erróneas o arbitrarias de órganos estatales. El primer régimen está previsto en el artículo 19 No 7 letra i) de la Constitución y en el artículo 10 de la Convención Americana de Derechos Humanos (CADH). Es conocido como indemnización por error judicial y se prevé para la operación por el Estado de su función jurisdiccional en el marco de un proceso penal ${ }^{4}$; es decir, está previsto frente al Estado-juzgador. El segundo régimen, regulado en el artículo 50 de la Ley No 19.640, Orgánica Constitucional del Ministerio Público (LOCMP), previsto para el ejercicio por la Fiscalía de sus funciones constitucionales, es decir, previsto frente al Estado-persecutor ${ }^{5}$. Para una mayor claridad explicativa, a estos dos regímenes los denominaré, en común, responsabilidad institucional del Estado (o simplemente responsabilidad institucional) para diferenciarlos de la responsabilidad civil (o responsabilidad civil extracontractual), regulada en la legislación civil. De ahí, entonces, se distinguirán dos subsistemas de responsabilidad institucional: el del Estado-juzgador y el del Estado-persecutor, según correspondiere. Es importante mencionar que además de la utilidad explicativa, esta diferenciación de nomenclatura se fundamenta en la diversa naturaleza jurídica que tiene la responsabilidad institucional del Estado respecto de la responsabilidad civil.

Estos dos subsistemas operan sobre la base de los mismos supuestos de hecho generadores de responsabilidad para el Estado (supuestos generadores): una 'actuación injustificadamente errónea' y una 'actuación arbitraria' (SCA, Rol 9732-2015, Considerando Tercero). En atención a que ambos sistemas operan sobre los mismos supuestos, las diferencias regulativas entre uno y otro son, para los efectos de este análisis, irrelevantes. Asimismo, los dos poseen una misma función de garantía con carácter reparatorio de la vigencia efectiva de los derechos fundamentales en el sistema de persecución penal.

A modo de digresión, me parece relevante precisar que el ámbito de protección de la responsabilidad institucional es, desde luego, un tema de radical importancia, pero que escapa a los límites de este trabajo. Por dicha razón, solo me permitiré esbozar el problema jurídico. La Corte Suprema ha declarado reiteradamente que el ámbito de protección de dicha responsabilidad solo cubre las afectaciones a la libertad personal y la seguridad individual. Al respecto, ha declarado que

el fundamento o ratio legis del derecho a ser indemnizado que consagra el artículo $19 \mathrm{~N}^{\circ} 7$ letra i) de la Constitución, es la afectación de la libertad personal del justiciable, pues el aludido derecho a indemnización forma parte del listado de "consecuencias" que el citado precepto constitucional deriva del "derecho a la libertad personal y a la seguridad individual" que asegura "a toda persona". Consecuencialmente, la alusión que el artículo $19 \mathrm{~N}^{0} 7$ letra i) de la Constitución efectúa al sometimiento a proceso obedece precisamente a las generalmente gravosas consecuencias que para la libertad personal del procesado implica su dictación, ya que salvo los casos de excepción en que el juez, por mandato o facultad legal, decrete su libertad provisional, el procesado quedará sujeto

\footnotetext{
Tabla de abreviaturas: Las referencias a sentencias se hacen de la siguiente forma: La palabra "sentencia(s)" se abrevia con una "S(s)". "CS" significa Corte Suprema y "CA", Corte de Apelaciones. A continuación se seńala el rol del proceso en el que se dictó y la fecha de dictado. "Cpp" significa Código procesal penal.

3 Entiendo por sistema de persecución penal al conjunto de normas y medios que el Estado pone a disposición de la comunidad para una adecuada resolución de los conflictos jurídicos que se suscitan a propósito de la ejecución de unas conductas que revisten los caracteres de delito (Navarro Dolmestch, 2018, pp. 25 y ss). Es equivalente al concepto de sistema de justicia criminal (Duce y Riego, 2007, pp. 16-17).

4 Este subsistema de responsabilidad institucional surge en la Constitución de 1925. Sobre el origen histórico en el Derecho constitucional de este instituto, véase Hernández (1979, pp. 89 y ss).

5 A su vez, este segundo subsistema de responsabilidad institucional surge con el dictado de la LOCMP.
} 
a prisión preventiva. (SCS Rol 33813-2017, Considerando Cuarto. También, en SsCS Rol 393682017, Considerando Quinto; Rol 4291-2014, Considerando Quinto; Rol 22356-2014, Considerando Cuarto; Rol 4921-2014, Considerando Quinto; y Rol 1579-2015, Considerando Cuarto).

Sin embargo, una atenta lectura de las disposiciones en juego muestra, en primer lugar, que tal restricción no puede desprenderse de esos textos normativos. Y, en segundo lugar, que la libertad personal y la seguridad individual no son los únicos derechos que pueden ser afectados por la actividad investigativa o la actividad juzgadora del Estado. La intimidad, la propiedad, el honor, la salud o la libertad económica, por nombrar algunos, son derechos que pueden tensionarse en el marco de una investigación o un proceso penales. Por tanto, si la responsabilidad institucional tiene un rol de garantía, de los derechos fundamentales, nada justifica restringir su ámbito de protección tan solo a la libertad personal y a la seguridad individual.

Volviendo al tema principal, en este artículo intentaré demostrar que el desarrollo jurisprudencial de la responsabilidad institucional se ha efectuado sobre la base de dos ideas claves: (a) una confusión entre la responsabilidad institucional y la responsabilidad personal del juez o del fiscal o funcionario del Ministerio Público por su propia actuación, y (b) la aplicación a la responsabilidad institucional de las categorías imputación propias de la responsabilidad civil del régimen común ${ }^{6}$. Estos supuestos se concretan en la aplicación a la responsabilidad institucional de un criterio fáctico de imputación consistente en el dolo o culpa del agente estatal actuante, lo que obliga a indagar sobre las motivaciones del juez o fiscal que adoptó una decisión. El recurso a este criterio fáctico se debe a la pretendida presencia de ingredientes subjetivos en los supuestos generadores de responsabilidad institucional que, por mediar dolo o culpa, podrían ser calificables como supuestos de error injustificado o de arbitrariedad.

Esta forma de interpretar la responsabilidad institucional del Estado juzgador y persecutor produce como consecuencia fenomenológica una reducción considerable del universo de casos indemnizables -lo que ha sido declarado expresamente, en forma descriptiva, por la Corte Suprema-, restringiéndola a las actuaciones dolosas o culposamente erróneas o arbitrarias. Como consecuencia normativa, se impide que estos regimenes desarrollen en forma efectiva su función de garantía de los derechos fundamentales en el sistema de persecución penal.

Como solución a los problemas anteriores, propongopor un lado, la separación conceptual de la responsabilidad institucional del régimen de responsabilidad civil y la "filiación" de aquel dentro del género "responsabilidad del Estado"; y por otro, la normativización de sus elementos generadores, superando el carácter fáctico de ellos. Por esta vía, se estima que la responsabilidad institucional podría llegar a desarrollar su función de garantía de forma más efectiva.

\section{La responsabilidad institucional y sus elementos generadores}

En 1983, Soto Kloss reflexionaba sobre el difícil camino que se ha recorrido en materia de responsabilidad del Estado. “¿Qué pasa [se preguntaba] que ha costado tanto para que pueda admitirse la responsabilidad del Estado por los diferentes dańos que puede originar, provocar y producir la actividad judicial, sea por actos jurídicos (resoluciones), sea por su actividad material?” (p. 49). Y aunque desde entonces se ha

\footnotetext{
De hecho, cuando la Corte Suprema efectúa declaraciones sobre el contenido de los supuestos generadores de responsabilidad, cita como apoyo doctrinal la conocida obra de Barros, Tratado de responsabilidad extracontractual (2012). Es lo que ocurrió, por ejemplo, en la SCS Rol 233-2017, Considerando Séptimo; SCS Rol 41.934-2017, Considerando Cuarto; SCS Rol 12505-2019, Considerando Séptimo. Asimismo, la Corte Suprema ha calificado expresamente a la responsabilidad institucional del Estado-persecutor como "responsabilidad extracontractual”. Al respecto, ver Sentencia Rol 41934-2017, Considerando XXX.
} 
avanzado en la regulación legal de esta responsabilidad (Barros, 2012, pp. 488-496), el interrogante de Soto Kloss sigue aún casi con la misma vigencia y urgencia: a pesar del reconocimiento constitucional del error judicial (artículo 19 No 7 letra i de la Constitución y artículo $10 \mathrm{CADH}$ ) y de la acción de indemnización por actuaciones del Ministerio Público (artículo 50 LOCMP), los casos en los que se ha declarado la responsabilidad institucional del Estado parecieran seguir siendo escasos.

El Derecho chileno regula, al menos, dos modelos macro de responsabilidad: (a) el contenido en la legislación civil de aplicación general, cuyo supuesto generador es la causación dolosa o negligente de un daño (artículo 2329 Código Civil), y (b) el articulado a partir del inciso segundo del artículo 38 de la Constitución, que actúa como garantía frente a la afectación de derechos fundamentales ${ }^{7}$. Aunque la jurisprudencia ha identificado la responsabilidad institucional del Estado juzgador y persecutor como especies de esta última responsabilidad del Estado, sin embargo, la ha interpretado como un tercer régimen de responsabilidad, con los mismos requisitos de configuración que la responsabilidad civil general (contractual y extracontractual). La responsabilidad del Estado y la regulada en el Código Civil son fenómenos diferentes, con fundamentos disímiles y con una regulación normativa que impide interpretar al primero como si se tratara del segundo.

Desde luego, el tenor literal del artículo 19 No 7 literal i) de la Constitución y el del artículo 5º LOCMP no ayudan a destacar el carácter garantista de la responsabilidad institucional (y, de hecho, contribuyen a interpretarla como si se trata de una responsabilidad civil). Mi tesis es que la necesidad de operar la garantía frente a un proceder injusto de los tribunales o de los fiscales obliga a reinterpretar esas disposiciones. La aplicación a la responsabilidad institucional de fórmulas o parámetros previstos para la responsabilidad civil terminan por negar el fundamento garantista de aquella.

Este problema se ha producido, a mi juicio, por una interpretación equivocada de los supuestos generadores de la responsabilidad del Estado juzgador y persecutor: se ha visto en la no justificación del error y en la arbitrariedad, elementos que deben ser analizados conforme a estándares de reprochabilidad personal (dolo o culpa, es decir, elementos de carácter fáctico) y, por ello, conforme a las categorías del derecho civil.

En el sistema de persecución penal, el caso de cada imputado que estuvo privado de libertad por la imposición de la prisión preventiva y que posteriormente se decida no perseverar en el procedimiento, sea sobreseído definitivamente o absuelto, o cada caso de exclusión de medios de prueba por haber sido obtenidos con infracción de derechos fundamentales, por nombrar algunos ejemplos, deberían ser serios candidatos a la reparación de los daños sufridos, tal como se lo preguntaba Hernández (1979, p. 188).

Disposiciones como el artículo 19 No 7 letra i) de la Constitución o el artículo $5^{\circ}$ de la LOCMP son producto de una larga evolución en materia de responsabilidad del Estado, que partió por un primer estadio de la negación del deber de reparación, fundado en su infalibilidad o la indiferencia de este,

pasando por un sistema de responsabilidad personal del funcionario, y dentro del mismo, una responsabilidad de la Administración por el hecho de su agente en forma subsidiaria, para llegar a sistemas en que se prescinde de la participación del funcionario, asumiendo una responsabilidad por la falta de servicio y más adelante, pero excepcionalmente, una responsabilidad objetiva o por el riesgo (Bermúdez, 2002, p. 254).

Esta clase particular de responsabilidad institucional se encuentra desarrollada en el artículo $4^{\circ}$ y $42^{\circ}$, ambos de la Ley No 18.575 , Orgánica Constitucional de Bases Generales de la Administración del Estado, y en el artículo 152 de la Ley No 18.695 (LOCBGAE) Orgánica Constitucional de Municipalidades. Ambas tienen fundamento positivo constitucional directo en el inciso segundo del artículo 38 de la Constitución, tanto en la explicación subjetiva como objetiva. Al respecto, véase Cordero (2010, pp. 54 y ss, y 64 y ss). 
Ballivian (2013), sostiene que la falta de eficacia de la indemnización por error judicial puede ser suplida por la responsabilidad por actuaciones del Ministerio Público (p. 55). Aunque los dos subsistemas de responsabilidad institucional del Estado-juzgador y del Estado-persecutor operan dentro del sistema de persecución penal, no concuerdo con esa opinión, porque considero que ambos regímenes, aunque pueden ser complementarios y hasta acumulativos, lo cierto es que los dos operan sobre supuestos completamente diferenciados. El error judicial lo es por resoluciones judiciales, mientras que la responsabilidad del Ministerio Público lo es por actuaciones del órgano de persecución penal.

Sobre estas acciones por responsabilidad institucional del Estado juzgador y persecutor hay escaso desarrollo dogmático, pero la casi idéntica redacción de los supuestos generadores del artículo $5^{\circ}$ LOCMP con los previstos en el artículo 19 No 3 letra i) de la Constitución para el error judicial, permite extrapolar a ambas los desarrollos realizados a propósito de una u otra. Es efectivo que existen diferencias entre los dos subsistemas de responsabilidad institucional, pero, en lo que aquí interesa, ambas comparten los mismos presupuestos generadores, consisten en una actuación injustificadamente errónea o una actuación arbitraria. En el caso de la responsabilidad institucional del Estado-juzgador esta actuación adopta la concreta forma de una resolución judicial dictada dentro de un proceso penal; en el de la del Estadopersecutor, la forma de decisión adoptada por el Ministerio Público en el ejercicio de sus funciones constitucionales (dirigir la investigación, ejercer la acción penal y proteger a las víctimas y testigos).

\section{Carácter de garantía de la responsabilidad institucional}

“[P]odría decirse que la 'responsabilidad del Estado' viene a coronar el régimen denominado Estado de Derecho, y a darle plenitud y sentido a la primacía del Derecho en la articulación política y social de una comunidad humana" (Kloss, 1983, pp. 51-52). De allí que la responsabilidad institucional tenga un carácter de garantía de la vigencia de los derechos fundamentales de las personas dentro del sistema de persecución penal.

Al igual que la prevista en el artículo 19 No 7 letra i) de la Constitución, la acción especial del artículo 5 LOCMP se concreta en la posibilidad de condenar al Estado al pago de una indemnización que tienda a resarcir o reparar el daño causado ${ }^{8}$. La acción tiene un carácter de garantía de los ciudadanos frente al Estado cuando este ejerce la función jurisdiccional a través de sus tribunales o las que le ha asignado al Ministerio Público, previstas en el artículo 83 de la Constitución (Montt, 1999, pp. 476 y ss). Este carácter de garantía no debe perderse de perspectiva, ya que la determinación de sus presupuestos de aplicación debería interpretarse conforme al principio favor libertatis.

En la interpretación jurisprudencial restrictiva de esta acción por responsabilidad institucional del Estado juzgador y persecutor se ha declarado que, sobre la base de los presupuestos generadores de responsabilidad (actuación arbitraria o injustificadamente errónea) se configura "un factor de atribución de responsabilidad mucho más restrictivo que el de los supuestos generales de la responsabilidad administrativa o de falta

\footnotetext{
El ordenamiento jurídico chileno limita la responsabilidad institucional al deber de indemnizar los dańos. Así, la Constitución prescribe que la persona que ha sido perjudicada por el error "tendrá derecho a ser indemnizad[a] por el Estado de los perjuicios patrimoniales y morales que haya sufrido" (artículo 19 No 7, literal i); mientras que la LOCMP dispone expresamente que la acción que prevé en su artículo $5^{\circ}$ tiene una naturaleza "patrimonial". En una perspectiva de lege ferenda, la restricción patrimonial prevista actualmente podría ser objeto de revisión. Ello, no solo por la necesidad de compatibilizar restrictivo sistema de reparación previsto en la legislación interna con el evidentemente más extenso adoptado por el artículo 63.1 CADH, sino porque la sola indemnización en dinero puede no ser suficiente para reparar los daños producidos, o no necesariamente puede satisfacer la expectativa de justicia de la persona afectada.
} 
de servicio" (SCS Rol 8095-2015, Considerando Cuarto) ${ }^{9}$. Esta comprensión del fenómeno ha generado críticas de la doctrina ${ }^{10}$.

Tanto la configuración normativa de un sistema de responsabilidad institucional como la forma en que este se aplique, supone una decisión y una disyuntiva entre dos opciones que determina la posición que puede adoptarse frente a dos valores que entran en juego. El primero consiste en que la responsabilidad institucional desarrolle siempre su rol de garantía; el segundo, en la protección de los intereses patrimoniales del Estado. Así, dependiendo de a cuál de esos valores se les dé preeminencia, el sistema de responsabilidad institucional por el que se opte puede estar entre un sistema en extremo objetivo (cualquier persona privada de libertad debe ser reparada si después se le absolvió, sobreseyó o se decidió no perseverar) y uno en extremo subjetivo (la reparación solo procede si el juez o fiscal actuante incurrieron en un acto doloso o culposo). Como intentaré mostrar seguidamente, el desarrollo jurisprudencial que se ha efectuado de los dos subsistemas de responsabilidad institucional se sitúa más cerca del extremo subjetivo, adoptando una interpretación restrictiva, de dudosa orientación garantista (Zúñiga, 2009, pássim).

\subsection{La actuación institucional y la actuación personal}

El primer motivo para dicha interpretación restrictiva del régimen de responsabilidad institucional consiste, a mi juicio, en que la jurisprudencia ha confundido, indebidamente, la actuación institucional con la actuación personal del juez, el fiscal o el funcionario del Ministerio Público. Tal confusión hace que la declaración de responsabilidad del Estado pase por la constatación de una actuación ilícita por parte del sujeto individual. Para evitar "[c]ensurar excesivamente la conducta de los jueces del crimen [que] importaría eventualmente un debilitamiento de la justicia, porque algún margen de error en la conducción de los procesos es inevitable" (Barros, 2012, p. 525), (hipótesis que es trasplantable a la responsabilidad del Ministerio Público), se adoptaría esta comprensión restrictiva. Este motivo subyace al argumento esgrimido por la Corte de Temuco, cuando esta declaró que

la revisión judicial de la actividad del Ministerio Público, al constituir una excepción a la autonomía determina que ella deba ser interpretada restrictivamente en el sentido de asegurar dicho espacio mínimo de acción requerido para el cumplimiento de los objetivos y fines encomendados por la Carta Fundamental. (SCA, Rol 560-2012-Civil, Considerando Quinto).

Una correcta interpretación de la responsabilidad institucional debería hacer desaparecer esta preocupación, que parece haber inclinado la balanza a favor de una interpretación restrictiva de tipo subjetiva: el Estado solo tiene acción para repetir en contra del fiscal o funcionario por actuaciones dolosas o gravemente negligentes de este y no en todos los casos, y lo mismo respecto de los jueces ${ }^{11}$. Lo anterior significa que la responsabilidad del Estado es independiente de la existencia de una actuación reprochable de un juez o un fiscal y ella podría configurarse, incluso, sin vinculación directa a una actuación de las personas señaladas, como el caso de responsabilidad por falta de control, déficits de regulación o de procesos de trabajo (falta

\footnotetext{
Esta misma expresión, en el sentido antes indicado, es reiterada en SCS Rol 29801-2015, Considerando Séptimo; SCS Rol 16527-2015, Considerando Tercero; SCS Rol 16978-2016, Considerando Octavo; SCS Rol 30956-2016, Considerando Cuarto; y SCS Rol 52932-2016, Considerando Duodécimo. En el mismo sentido, con otras expresiones, SCS Rol 14421-2013, Considerando Octavo; SCS Rol 16978-2016, Considerando Noveno; SCS Rol 30956-2016, Considerando Quinto; SCS Rol 52932-2016, Considerando Décimo tercero.

10 Confróntese, Zúñiga (2008); y Precht (2004).

11 En el Derecho administrativo, el artículo 44 LOCBGAE hace la distinción entre la "falta de servicio", por un lado, y la "falta personal", por otro. Esta técnica es más que la utilizada en el artículo $5^{\circ}$ LOCMP, aunque sobre la base de los dos textos normativos puede llegarse a la misma conclusión: la generación de responsabilidad institucional no requiere la producción de responsabilidad personal del agente estatal que actúa. En el caso de la responsabilidad del Estado-juzgador, y aunque la Constitución no contiene mención expresa en el artículo 19 No 7 letra i), su interpretación sistemática permite arribar, nuevamente, a la misma conclusión anterior.
} 
de gestión) o retardo en el ejercicio de sus funciones. El segundo, porque la responsabilidad institucional -como más adelante intentaré demostrar- no requiere de una actuación intencional o negligente de un sujeto (fiscal o juez), sino de la constatación de la infracción de un deber, por lo que declarar la responsabilidad del Estado de ninguna forma implica un juicio sobre la actuación personal de un sujeto.

La vinculación entre la actuación institucional y la actuación personal del juez o fiscal queda de manifiesto en el concepto mismo de actuación injustificadamente errónea o actuación arbitraria. Jurisprudencialmente se ha definido una actuación injustificadamente errónea como aquella "carente de toda justificación, sin motivo o causa plausible, sin asidero racional, colofón de un error craso; en otras palabras, que nadie puede ser sujeto pasivo de un procedimiento judicial de índole criminal sino con fundamentos justificados" (SCS Rol 7720-2010, Considerando Tercero. En el mismo sentido, ver SCS Rol 5911-2011, Considerando Décimo tercero). Por otro lado, "supone que la conducta errónea [...] sea antojadiza o que esté dirigida por la irracionalidad... contrario a la lógica, a los dictados de la experiencia y a los conocimientos sobre la materia... o bien que derive de la sola voluntad o del capricho del órgano persecutor" (SCS Rol 106682015, Considerando Quinto). La Corte Suprema ha sintetizado el sentido del error injustificado de la siguiente forma:

a) un error inexplicable; b) desprovisto de toda medida que lo hiciera comprensible; c) falto de toda racionalidad; d) sin explicación lógica; e) un error grave, exento de justificación, sin fundamento racional, inexplicable; f) un error craso y manifiesto, que no tenga justificación desde un punto de vista intelectual en un motivo plausible; g) actuación adoptada insensatamente; y h) motivado por el capricho, comportamiento cercano al dolo (SCS Rol 671-2013, Considerando Vigésimo séptimo; posteriormente reiterado en SsCS Rol 14421-2013, Considerando Quinto; Rol 12451-2014, Considerando Quinto; Rol 16527-2015, Considerando Tercero; Rol 4739-2017, Considerando Sexto; Rol 41934-2017, Considerando Cuarto; Rol 38096-2017, Considerando Quinto; Rol 2332017, Considerando Séptimo; SCA Santiago Rol 9732-2015, Considerando Quinto. ${ }^{12}$.

Por su parte, más críptica ha sido la caracterización de la arbitrariedad. Para la Corte, una actuación es arbitraria cuando "depende del arbitrio", es decir que "sea antojadiza, que esté dirigida por la irracionalidad o que responda al mero capricho" (SCS Rol 5911-2011, Considerando Décimo tercero).

\subsection{La responsabilidad institucional como responsabilidad civil general}

Interpretar la responsabilidad institucional como si se tratara de una responsabilidad civil general, proveniente del incumplimiento de un contrato o de la producción de un daño patrimonial, significa que su configuración requeriría la actuación de un sujeto específico (fiscal o juez) y que esta le sea imputable subjetivamente, a título intencional o negligente. Esta forma de interpretar el régimen de responsabilidad institucional se refleja, principalmente, en el desarrollo del concepto de "actuación arbitraria" y, en menor medida, en el de "actuación injustificadamente errónea"13, tal como se analizará en el párrafo siguiente.

12 Estas expresiones de la SCS Rol 671-2013 corresponden a una cita a la obra de Barros (2012, pp. 524-525), que la Corte asume como una opinión del autor. Sin embargo, al revisar la fuente se puede constatar que lo citado por la Corte no es la opinión de Barros, sino que una cita que este mismo hace de sentencias de dicho Tribunal. Entonces, lo que la Corte hace en la sentencia referenciada, es citarse a sí misma.

13 La condición de falta de justificación ("injustificadamente") se aplica en el desarrollo jurisprudencial tanto al error como a la arbitrariedad. Esta conclusión es errada no solo según el tenor literal de las disposiciones en juego (dicha condición literalmente solo se aplica a la actuación errónea), sino también de acuerdo con una interpretación lógica de estas. En efecto, por definición, la arbitrariedad siempre será "injustificada", sin excepciones. Por lo anterior, la lectura correcta de las disposiciones debe hacerse en el sentido de una actuación arbitraria, por un lado, o injustificadamente errónea, por otro. 
En síntesis, el problema radica aquí en el carácter fáctico que los tribunales le han dado a la arbitrariedad y al error, de forma que su determinación pasa por una averiguación de la subjetividad del sujeto que ejecutó la actuación, es decir, por un dato de la realidad que se encuentra en la psiquis del sujeto actuante. En cambio, creo que tales elementos deben ser interpretados con un sentido normativo, es decir, como la constatación de una infracción de deberes, de lo que se desprenden dos consecuencias: (a) que el elemento generador de la responsabilidad no es solo y necesariamente la actuación de un sujeto concreto, sino que también puede derivarse de la adopción institucional de procesos de gestión o de criterios de actuación; y (b) que la subjetividad y la motivación con la que se ejecutó la actuación son irrelevantes, de modo que su averiguación es innecesaria, tanto para los aspectos probatorios del proceso sobre la determinación de la responsabilidad como para la configuración de ella.

\section{4. El carácter fáctico de los criterios de imputación}

Entiendo que los elementos generadores de responsabilidad (actuación injustificadamente errónea/ actuación arbitraria) han sido entendidos por la Corte Suprema (y de ahí, por los demás tribunales) con un carácter esencialmente fáctico, ya que la configuración de estos elementos generadores de responsabilidad exige una indagación sobre cuestiones de hecho consistentes en las percepciones y motivaciones de los sujetos que verificaron la actuación; aquí la pregunta relevante se sintetiza en la apreciación que el sujeto actuante haya tenido de los hechos o en la intencionalidad de este.

Esto ha ocurrido porque los tribunales han interpretado los supuestos generadores de la responsabilidad institucional como si esta se tratara de la responsabilidad civil general, requiriendo para su configuración la constatación de un hecho doloso o culposo y una relación de causalidad entre la conducta y el resultado. Por ejemplo, la Corte Suprema declaró que

no hay hechos objetivos que demuestren que la adopción de medidas de protección que pudiere haber realizado el Ministerio Público habría evitado la muerte de la señora A.M.C., esto es, no hay elementos idóneos que permitan determinar con algún grado de certeza la relación de causalidad que a estos efectos se requiere entre la conducta injustificadamente errónea o arbitraria que se imputa al Ministerio Público y el resultado dañoso que justifica la pretensión de la demandante. (SCS Rol 42522009, Considerando Undécimo.).

Esta aplicación de las categorías propias de la responsabilidad civil desconoce, por un lado, el carácter garantista de la responsabilidad institucional, pero también desconoce que esta se desenvuelve en un escenario distinto al que incumple un contrato u ocasiona un daño. Este distinto escenario está representado por la actuación institucionalizada de órganos estatales (tribunales o fiscalía), en los que la concreta actuación de un fiscal o un juez debería ser, en principio, irrelevante en la configuración de la responsabilidad institucional. Como acertadamente, a mi juicio, advierte Barros (2012), la comprobación de la responsabilidad institucional no

exi[ge] juzgar el comportamiento ministerial de los jueces [y de los fiscales, se podría agregar sin alterar el sentido], porque de acuerdo con los principios de la responsabilidad extracontractual, la comprobación del ilícito civil o de la falta de servicio exige juzgar objetivamente los hechos, sin que ello necesariamente suponga un juicio personal de reproche. (p. 525). ${ }^{14}$

14 En este caso, la expresión "responsabilidad extracontractual" es usada por Barros en el mismo sentido que en este artículo se usa la expresión "responsabilidad institucional". 
En efecto, cuando el elemento "actuación injustificadamente errónea" se entiende como sinónimo de una actuación basada en una apreciación que no se corresponde con la realidad "respecto del cual no le asiste una justa causa y que, por ende, ha sido causado sin mediar mala fe" (SCA Temuco Rol 560-2012-Civil, Considerando Quinto), se está haciendo referencia a una cuestión de hecho cuyo contenido se concreta en la apreciación que el fiscal o el juez tienen de los hechos, la que resulta ser falsa, es decir, sin correspondencia con la realidad. La no justificación de una actuación errónea se manifiesta en que el juez o el fiscal pudieron abrir más los ojos y ver mejor los hechos que se les presentaban. Mientras que en el caso de la actuación arbitraria, esta se ha entendido como una actuación carente de racionalidad o en los casos en los que la "razón jurídica" es desplazada por la "razón personal" del fiscal o el juez. Es decir, atiende a los procesos mentales — cuestión también fáctica— sobre los cuales el juez o fiscal adoptó una decisión o dejó de actuar cuando era debido. Esto ocurre cuando la arbitrariedad se entiende como

una conducta orientada a la producción de un daño, es decir, existe una determinación precisa del agente público — fiscal — en orden a ejercer la función persecutoria apartándose tanto de las bases mínimas de lógica y racionalidad como de los fines propios del cargo, con el objeto de causar un daño injusto en la persona o los bienes de un ciudadano. (SCA Temuco Rol 560-2012-Civil, Considerando Quinto).

Su determinación pasa por la indagación de la motivación del juez o del fiscal al ejecutar la conducta objeto del juicio de responsabilidad.

Esta interpretación fáctica ha llegado a generar un argumento novedoso en la jurisprudencia: la CA de Temuco ha recurrido al concepto de la personal percepción racional del fiscal para la apreciación de los hechos conforme con el estado de la investigación (SsCA Temuco Rol 2288-2008, Considerando Cuarto; y Rol 1903-2008, Considerando Sexto), criterio que, conociendo del recurso de casación en el fondo intentado por el demandante, la Corte Suprema validó:

los sentenciadores del grado estimaron que la actuación del fiscal - representante del Ministerio Público - no había sido "injustificadamente errónea o arbitraria”. Para llegar a esa conclusión no sólo se consideró "que la etapa procesal en que se encontraba la causa era de investigación, en que el nivel de certeza exigible para la imputación de un hecho resulta satisfecha prima facie con las diligencias de investigación a la fecha realizadas" y que la conducta del ente persecutor "se ajustó al procedimiento según su personal percepción racional que tenía" -que es la crítica que efectúa el recurrente al alcance que los sentenciadores habrían dado al artículo 5 de la Ley N 19.640. (SCS Rol 2762-2009, Considerando Décimo sexto).

Por la vía de considerar a los presupuestos de la responsabilidad institucional del Estado desde una perspectiva fáctica, se puede llegar, incluso, a sostener que la exigencia de falta de justificación

la requiere la actividad investigativa criminal, la que como otra cualquiera realizada por el ser humano está expuesta a incurrir en equivocaciones o desaciertos, los cuales son explicables a causa de las limitaciones inherentes a la naturaleza del hombre, de cuyas virtudes y defectos participan, como es obvio, los fiscales. (SCS Rol 2762-2009, Considerando Décimo sexto; posteriormente reiterada en SCA Concepción Rol 1548-2013, Considerando Sexto).

Como se comprenderá, la vía argumentativa del "error humano" puede conducir fácilmente a la anulación jurisprudencial de la responsabilidad institucional del Estado, porque es evidente que casi cualquier error pueda llegar a estar justificado por ser precisamente un error humano. El problema, en este punto, es 
si la garantía de los ciudadanos frente al Estado-persecutor permite que estos deban soportar errores, independiente del grado de aquellos. Hernández (1999) se manifiesta expresamente sobre el punto, cuando propone que la disposición constitucional sobre el error judicial (aplicable al de la acción del artículo 5 LOCMP) debería (no queda claro si en perspectiva de lege ferenda o lege data) "hacer responsable al Estado por toda actuación u omisión objetivamente antijurídica, entendiendo que esta antijuricidad objetiva se da cada vez que un administrado sufre un perjuicio que no está obligado a soportar" (p. 471) ${ }^{15}$.

En atención a que una interpretación en sentido fáctico de los elementos generadores de la responsabilidad civil conduce a una necesaria restricción de la aplicación de la garantía de protección frente al Estado juzgador y persecutor, su superación es deseable. Lo anterior, considerando, adicionalmente, que en la disposición del artículo $10 \mathrm{CADH}$, el derecho a ser indemnizado procede por haberse dictado una sentencia condenatoria firme solamente fundada en un error judicial, sin que este sea calificado como injustificado y sin que se adicione a la arbitrariedad como elemento generador; y que la garantía del inciso segundo del artículo 38 de la Constitución protege a los administrados frente a una lesión de sus derechos sin exigir elementos de configuración adicionales.

\section{Independencia de la responsabilidad institucional de la responsabilidad civil}

Una primera cuestión a despejar se relaciona con la independencia no solo normativa, sino también conceptual de la responsabilidad institucional del Estado juzgador y persecutor, de la responsabilidad civil regulada en el derecho común. Un fundamento positivo para esta separación consiste en que no existe disposición alguna que permita establecer una vinculación sistemática entre las regulaciones del artículo 19 No 7 letra i) de la Constitución y el artículo 5 LOCMP, con las contenidas en el Código Civil. En efecto, no existe referencia alguna en las disposiciones en juego, de modo que desde la literalidad normativa no hay relación entre ambos regímenes de responsabilidad. Dado que, a mi juicio, el punto es demasiado importante como para resolverlo solo en atención a elementos literales, el argumento que considero más persuasivo consiste en la función de unos y otro régimen. La responsabilidad del derecho común se fundamenta en la idea aristotélica de la justicia conmutativa, conforme a la cual "se trata de obtener una restauración de la desigualdad que se ha producido por la acción del que causa un dańo" (Corral, 2013, p. 67), por lo que su función se desempeńa, esencialmente, en el marco de las relaciones privadas. La responsabilidad institucional del Estado juzgador y persecutor, en cambio, tiene una función de garantía de derechos fundamentales y por eso esta está llamada a desenvolverse en un ámbito público.

Por otro lado, aunque la inexistencia de estas referencias normativas entre la responsabilidad del Estado juzgador y persecutor, y la responsabilidad del Estado-administrador impide relacionarlas positivamente, soy de la opinión, sin embargo, que estas sistemáticamente sí se encuentran emparentadas por la función de garantía que ambas desempeñan. En este caso, el parentesco se establece no directamente por la disposición

La Corte Suprema ha sido especialmente enfática en descartar reiteradamente el carácter objetivo de la responsabilidad institucional. Así, ha declarado que "el hecho que se haya emitido un veredicto absolutorio no transforma automáticamente la medida cautelar personal de privación de libertad en injustificadamente errónea o arbitraria, pues se trata de dos momentos procesales diferentes que requieren de grados de convicción distintos, con procesos valorativos e interpretativos diversos y en consecuencia, ambas perfectamente válidas y jurídicamente correctas" (SCS Rol 5270-2008, Considerando Décimo quinto. Criterio posteriormente reiterado en SsCS Rol 398-2010, Considerando Octavo; Rol 2804-2010, Considerando Décimo Cuarto; Rol 3075-2015, Considerando Quinto; Rol 22498-2014, Considerando Sexto; Rol 25685-2014, Considerando Octavo; Rol 83373-2016, Considerado Séptimo; Rol 44656-2018, Considerando Séptimo; Rol 211652019, Considerando Quinto; y Rol 29629-2019, Considerando Séptimo). Asimismo, que "la sola circunstancia que los actores hayan sido sobreseídos conforme con lo establecido en el artículo 250 letra a) del Código Procesal penal, no determina la responsabilidad del Ministerio Público, toda vez que el estándar de conducta exigible debe contrastarse con los antecedentes con que contó la referida institución en las distintas etapas de la investigación" (SCS Rol 4.739-2017, Considerando Séptimo). 
contenida en el inciso segundo del artículo 38 de la Constitución (aplicable solo a la Administración por su tenor literal), sino a través de sus artículos $6^{\circ}$ y $7^{\circ}$ (Bermúdez, 2002, p. 253), de modo que tanto la del Estado juzgador y persecutor como la del administrador, se presentan como mecanismos de responsabilidad que tienen por objeto proteger los derechos fundamentales frente a actuaciones estatales que los lesionen. En otras palabras, que los tres regímenes de responsabilidad (juzgador, persecutor y administrador) comparten su naturaleza de ser una protección del ciudadano frente a las actuaciones estatales, un fundamento radicalmente diferente del que tiene el sistema de responsabilidad de la legislación civil.

Este parentesco obliga a aplicar a la responsabilidad del Estado juzgador y persecutor unos estándares similares que produzcan como resultados una extensión similar del universo de casos indemnizables. En este punto, perplejidad produce el hecho que sea más fácil obtener del Estado la reparación de los daños sufridos las lesiones a una persona por el mal estado de una acera, que aquellos que debe padecer quien estuvo privado de libertad y es posteriormente absuelto o sobreseído, o el caso de la negativa sin fundamento del Ministerio Público a formalizar una investigación, asfixiando la expectativa constitucionalmente fundada de la víctima al enjuiciamiento de los hechos constitutivos de delitos y que la han afectado ${ }^{16}$.

El universo de casos potencialmente indemnizables por la responsabilidad del Estado-administrador es sustancialmente mayor que en el del Estado juzgador y persecutor, básicamente porque en el primero no se exige la verificación de un comportamiento doloso o culposo de un funcionario de la Administración; en ella "mientras la conducta dañosa provenga de la actividad administrativa y sus órganos, le es imputable responsabilidad” (Cordero, 2010, p. 171). Asimismo, se ha sostenido que la garantía del artículo 38 de la Constitución implica que "el legislador no puede intermediar el comportamiento del funcionario como mecanismo de entrabamiento del sistema de responsabilidad" (p. 173) ${ }^{17}$.

La diferencia fundamental entre ambos regímenes se encuentra en que mientras la responsabilidad institucional opera sobre una concepción jurisprudencial de carácter fáctico del error y la arbitrariedad del agente estatal como sus elementos generadores, la del Estado-administrador lo hace sobre la concepción de "falta de servicio", de claro tinte normativo, entendida como "una mala organización o funcionamiento defectuoso de la Administración, ambas nociones apreciadas objetivamente y referidas a lo que puede exigirse de un servicio público moderno, y lo que debe ser su comportamiento normal" (Pierry, 2000, p. 11) o como "el funcionamiento irregular o defectuoso de la función administrativa, debiendo apreciarse la misma no en relación a la culpa del agente sino de acuerdo de las leyes y reglamentos que rigen la función (el servicio) y al daño causado al administrado" (Cordero, 2012, p. 60).

La premisa de la independencia normativa y conceptual de la responsabilidad institucional en el sistema de persecución penal del régimen común del derecho civil tiene varias derivadas, de las que me interesa destacar una en particular. Esta consiste en que, a diferencia de lo que ocurre en la responsabilidad civil, en la configuración de la responsabilidad institucional, el dolo y la culpa del agente estatal (juez, fiscal o funcionario del Ministerio Público) no debería cumplir función alguna. Es efectivo que la literalidad de la fórmula que usa el legislador para definir los supuestos generadores de la responsabilidad institucional

${ }_{16}$ Esta asimetría entre el desarrollo de la responsabilidad del Estado-administrador y el rezago de la del Estado-juzgador no es exclusiva de Chile. Al respecto, ver Tornos (1985), p. 72. Si en el ámbito de la responsabilidad de la Administración del Estado la legislación española se ha situado en un lugar pionero dentro de la normativa europea, no puede afirmarse lo mismo en relación con la responsabilidad derivada de la actividad judicial. Mientras la Administración responde por toda lesión derivada del funcionamiento normal o anormal de un servicio público, de manera que basta con demostrar la existencia de una lesión para que la sociedad deba reparar al injustamente perjudicado, en el supuesto de la actividad de jueces y magistrados administrando justicia tan solo se contempla la responsabilidad personal derivada de falta o delito, reconociéndose excepcionalmente la responsabilidad directa del Estado en el caso de error constatado en un recurso de revisión penal.

17 Lo anterior, claro está, con los matices propios de una materia en la que no se ha alcanzado aún pleno consenso. Al respecto, ver Enteiche (2011), pp. 109-135. 
(actuación arbitraria o injustificadamente errónea) puede tentar al intérprete a incorporar en ella estos elementos subjetivos (solo puede ser arbitraria la actuación de una persona y, por ende, será muy probablemente dolosa; solo puede errar una persona y en la producción de ese error puede contribuir la negligencia); y que tales supuestos contrastan con el criterio aparentemente "objetivo" de la falta de servicio como elemento generador de la responsabilidad del Estado-administrador, lo que, a contrario sensu, podría llevar a concluir en el carácter esencialmente subjetivo de la del Estado juzgador y persecutor.

Pero estas conclusiones no son aceptables. El error y la arbitrariedad como elementos generadores de la responsabilidad del Estado juzgador y persecutor no pueden ser interpretados, ni en literalidad ni sistemáticamente, como elementos cuya configuración reclamen dolo o culpa del concreto sujeto actuante u omitente. Lo anterior, porque, en primer lugar, la responsabilidad del Estado-persecutor lo es por actuaciones erradas o arbitrarias del Ministerio Público, según el tenor literal del artículo $5^{\circ}$ LOCMP, y no del fiscal o funcionario de dicho órgano. Esto significa que la responsabilidad puede configurarse aun por actuaciones institucionalizadas no atribuibles en forma directa o inmediata a un fiscal o funcionario, como la lesión a un derecho fundamental que se produce por un procedimiento de trabajo defectuoso, por acumulación de cargas de trabajo que no se manejaron adecuadamente o no pudieron ser controladas, etc. Y, en segundo lugar, porque si la responsabilidad es del Ministerio Público, este no puede actuar dolosa o culposamente, toda vez que dichas condiciones solo son predicables de personas físicas.

En el caso de la responsabilidad del Estado-juzgador, la literalidad de la disposición constitucional parece impedir la conclusión sobre la atribución de responsabilidad al órgano Poder Judicial. Pero esa aprehensión es solo aparente: si se lee adecuadamente la disposición constitucional, el derecho es a ser indemnizado por el Estado respecto de una resolución judicial que, en los casos previstos en la norma, haya causado perjuicios patrimoniales y morales. Aunque una resolución siempre va a ser dictada por un juez o un tribunal colegiado, es decir, por unos funcionarios estatales específicos y determinados, una decisión errónea o arbitraria no necesariamente requiere un juez que incurra en un error (por no abrir mejor los ojos) o que actúe arbitrariamente, ya que la condición errada o arbitraria de la resolución puede ser imputable a defectos de funcionamiento u organización, como el caso de una resolución errada adoptada en el contexto de audiencias agendadas con escaso tiempo por cumplimiento de metas de gestión. Entonces, de lo que el Estado debe responder es de resoluciones erróneas o arbitrarias del Poder Judicial, al igual que el tenor literal del artículo 50 LOCMP respecto de la Fiscalía. En suma, entendida así la responsabilidad del Estado juzgador y persecutor, esta podría ser caracterizable como "objetiva”, en la que la "obligación de reparar debe ser configurada al margen de consideraciones culpabilísticas" (Corral, 2013 , p. 184), pero solo con relación al concreto agente que verificó la actuación ${ }^{18}$. Un problema distinto es la necesidad de un criterio de imputación respecto del órgano.

18 En la discusión de este problema en relación con la responsabilidad del Estado-administrador, Fiamma (1989) concluye en su carácter objetivo: "Condicionar la responsabilidad a la comisión de una 'falta de servicio' por parte de la Administración significa volverla a situar en el extremo del autor del dańo; aun cuando fundada en un nuevo tipo de ilicitud, que si bien no es igual a la del dolo o culpa, ya que es mucho más objetiva que ésta, mantiene el carácter delictual” (p. 438). La interpretación del artículo 38 de la Constitución propuesta es, así, más cercana al modelo español de responsabilidad, que opera sobre la base de una lesión y la relación de causalidad de aquella con una actuación defectuosa de la Administración (Martín Rebollo, 1999, pp. 345-346 y 362-363). Pierry (1996), en cambio, disiente de este criterio: "el artículo $4^{\circ}$ [LOCBGAE] tampoco establece la responsabilidad objetiva de la Administración, sino que 'reproduce el principio de responsabilidad del Estado' entendido [...] dentro de una noción que presupone el actuar ilícito o antijurídico y exigiendo por lo tanto 'culpa o dolo', lo que, referido a las instituciones de derecho público [...] se refiere a la 'culpa o dolo' del servicio, o sea a la falta de servicio" (p. 298). 


\section{La función del error y la arbitrariedad. Responsabilidad normativa}

Antes se ha dicho que la responsabilidad institucional del Estado juzgador y persecutor no es subjetiva en el sentido en el que lo entiende la doctrina civilista, porque su configuración prescinde de criterios de imputación de esa naturaleza. Pero tampoco es objetiva la otra categoría disponible en el sistema dual en el que los civilistas han entendido la responsabilidad, conforme a la cual "quien con su actividad irroga un daño, debe repararlo, haya o no dolo o culpa de su parte" (Corral, 2013, p. 84). Ello significa que no por prescindirse del dolo y la culpa, cualquier daño o lesión a los derechos fundamentales sea siempre, a todo evento, indemnizable.

Desde una perspectiva de lege ferenda, no alcanzo a estructurar buenas razones por las que la responsabilidad institucional pudiera actuar siempre a todo evento, sobre todo considerando que la actividad investigativa y juzgadora del Estado tiene, por su propia naturaleza, altas dosis de sacrificio de derechos fundamentales, sobre todo para el imputado. Mi opinión es que deberíamos transitar a un estadio positivo en el que, por ejemplo, cualquier privación de libertad que no sea seguida por una sentencia condenatoria, genere para el Estado el deber de resarcirla en forma automática. Pero mientras no se modifiquen la Constitución y la LOCMP, lo claro es que el régimen de responsabilidad institucional no puede operar automáticamente en sentido objetivo ${ }^{19}$.

La forma en la que están construidos los supuestos generadores de la responsabilidad institucional (actuación arbitraria o injustificadamente errónea) puede cumplir esa función de restricción, si ellos se consideran portadores de un criterio de imputación de carácter normativo, esto es, la infracción de deberes.

Una interpretación en clave normativa no ha estado ausente en la jurisprudencia. En un caso en que se verificó una interceptación ilegal de comunicaciones, la Corte Suprema declaró la responsabilidad institucional del Ministerio Público, declarando:

no obstante que el legislador dispuso de ciertos resguardos que estimó necesarios para intervenir las comunicaciones entre un imputado y su abogado, el Ministerio Público no respetó tales parámetros e impidió con ello que el órgano jurisdiccional resolviera acertadamente el conflicto que se suscita entre esa actuación y los derechos del imputado, entre éstos, el de la defensa jurídica. En efecto, se traspasó un ámbito reservado o protegido, en el cual los supuestos de intrusión y sus límites están expresamente regulados en la ley, incluyendo en la situación en estudio controles más estrictos por ser la intrusión más intensa. (SCS Rol 2765-2009, Considerando Duodécimo).

...habiendo ocultado los fiscales al juzgador el vínculo exacto que ligaba al afectado con la medida intrusiva y los imputados [defensor de estos], violó los límites fijados por el legislador que permiten salvaguardar la licitud de una actividad investigativa aun cuando pugne con garantías inconstitucionales (SCS Rol 2765-2009, Considerando Décimo tercero).

La fundamentación de la Corte, en este caso, prescinde de elementos fácticos, ya que no ausculta las motivaciones de los fiscales para practicar las interceptaciones de comunicaciones reprochadas. Una interpretación fáctica podría haber conducido a la Corte a declarar que, aunque no se reunían los requisitos legales para la interceptación telefónica, no se configuraba la responsabilidad institucional, por haberse constatado, por ejemplo, una actuación de buena fe de los fiscales o un excesivo celo investigativo con

9. Como el sistema que Fiamma (1989) reclamó en su momento para la responsabilidad del Estado-administrador, criticando el concepto de falta de servicio: "La Constitución no considera la conducta de la Administración para admitir su responsabilidad, basta que haya una víctima que no esté jurídicamente obligada a soportar el daño” (p. 438). 
el fin de ser lo más acucioso posible en el ejercicio de la función de investigar y, por ende, una actuación alejada del error o la arbitrariedad. En el caso señalado, en cambio, la Corte prescindió de un análisis fáctico y razonó sobre la base de la infracción por los fiscales de las normas legales que regulan la diligencia de interceptación de comunicaciones.

Un caso podría, en este punto, aportar elementos para ilustrar el problema, contenido en la SCS Rol 169782016, Considerando Séptimo. Los hechos, de acuerdo con la sentencia de casación, son los siguientes:

(a) El 23 de marzo de 2010, alrededor de las 17:30 horas, en la intersección de avenida P. de Valdivia con Caupolicán de la comuna de Carahue, R.A.B.J. fue sorprendido por personal de la Policía de Investigaciones de Chile, transportando en su pantalón 6 contenedores de papel con marihuana cuyo peso bruto alcanzó un total de 2,6 gramos de cannabis sativa. [La sentencia nada aclara sobre la forma en la que la policía descubrió el porte de esos escasos 2,6 gramos de cannabis sativa, elemento que también sería relevante para el análisis].

(b) El 24 de marzo de 2010, se llevó a cabo la audiencia de control de detención ante el Juez de Garantía de Carahue, decretando el tribunal la medida cautelar de prisión preventiva.

(c) El 17 de junio del mismo año se formuló acusación por parte del Ministerio Público, imputándole la autoría del delito de tráfico ilícito de pequeñas cantidades.

(d) Una vez desarrollado el juicio oral se dicta sentencia en los autos condenando a R.B.J. como autor del delito de tráfico en pequeñas cantidades de sustancias estupefacientes o sicotrópicas, previsto y sancionado en el artículo 4 de la Ley $\mathrm{N}^{\circ} 20.000$, en grado de consumado.

(e) Conociendo del recurso de nulidad interpuesto por la defensa del acusado, el 27 de diciembre de 2010, la Corte de Apelaciones de Temuco dicta sentencia que acoge el arbitrio de nulidad y en el fallo de reemplazo se absuelve al acusado estableciendo que no se encuentra acreditada la intención o ánimo de cometer el delito que se le reprocha.

El imputado absuelto dedujo la acción de indemnización del artículo 5 LOCMP. La Corte Suprema, conociendo por vía de casación en la forma y en el fondo declaró que, en la especie, no se había configurado una actuación injustificadamente errónea del Ministerio Público cuando decidió acusar al demandante

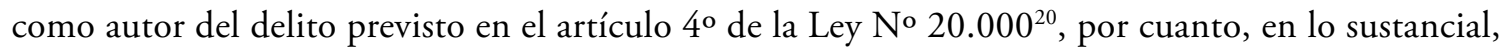

la acusación no fue fruto de un error manifiesto carente de todo sustento racional, sino que se fundó en una interpretación del artículo $4^{\circ}$ de la Ley $\mathrm{N}^{\circ} 20.000$ distinta de aquella sostenida por los magistrados que conocieron y fallaron el recurso de nulidad interpuesto por la defensa del acusado, quienes consideraron que diversas circunstancias acreditadas en el proceso daban cuenta que faltaba en el encartado el ánimo o la intención de traficar, descartando el elemento subjetivo, sin que se cuestionara que efectivamente aquel portaba la droga. (SCS Rol 16978-2016, Considerando Décimo).

Un elemento a considerar en el análisis es que estamos en el terreno del Derecho penal, en el que los márgenes de interpretación deberían ser acotados si nos tomamos en serio la legalidad penal. En esta perspectiva, ¿Cómo es posible que, sobre la base de unos mismos hechos judicialmente fijados, dos tribunales hayan llegado a conclusiones diametralmente opuestas? Esta diferencia de calificación jurídica (conducta típica

20 Ley No 20.000 sustituye la Ley No 19.366, que sanciona el tráfico ilícito de estupefacientes y sustancias sicotrópicas. 
en el fallo condenatorio/conducta atípica en el fallo de nulidad) no puede, razonablemente, justificarse en una legítima diferencia de interpretación del ámbito de tipicidad de la conducta, sino que, derechamente, en una interpretación antojadiza del tipo penal. Este error es predicable de la conducta del Ministerio Público por una doble vía: primero, por la ausencia de criterios de persecución penal, que plantea problemas de igualdad en la aplicación de la ley penal; y segundo, por la decisión de deducir acusación sin que el material fáctico permitiera acreditar la preordenación dolosa al tráfico de la sustancia estupefaciente portada por el acusado, hecho que habría transformado a la conducta en una conducta típica de tráfico de pequeñas cantidades de sustancias estupefacientes, conforme al artículo $4^{\circ}$ de la Ley No 20.000. La restricción a la libertad que pesó sobre el acusado (debió concurrir obligatoriamente a la audiencia de juicio, debió soportar -seguramente- medidas cautelares personales) no puede quedar entregada a una simple falta de acuerdo de los fiscales y jueces sobre el contenido de la conducta típica. En el caso descrito, sí es posible sostener que cuando el Ministerio Público decidió acusar, infringió su deber de objetividad, por cuanto llevó a juicio unos hechos que no eran típicos.

Un problema parecido al de la diferencia interpretativa de los tipos penales es el que se produce por la incorporación paulatina de información a la investigación y los estándares legales para decidir sobre la imposición de medidas cautelares personales y la absolución o condena. En efecto, un argumento muy recurrido por la jurisprudencia para descartar la configuración, principalmente de un error, que haga nacer responsabilidad institucional, consiste en que la decisión de imponer, por ejemplo, la prisión preventiva, se adoptó con la información de la que se disponía al momento de dictarse esa resolución ${ }^{21}$. Es cierto que ni el fiscal ni el juez que sobre el particular resuelven son adivinos de la información que, en el futuro, pueda llegar a esta disponible y que deje sin fundamento la prisión preventiva. Pero también es cierto, como lo expone Carocca Pérez (1987), que la evaluación sobre el surgimiento de la responsabilidad institucional de considerar a la investigación y al proceso penal como una unidad (p. 210).

Todo parece indicar que, en realidad, entre los dos elementos configuradores de la responsabilidad del Estado juzgador y persecutor que prevé nuestro Derecho no existirían diferencias sustanciales que justificaran su tratamiento por separado. Ello es posible de concluir si tales elementos se interpretaran en un sentido normativo, como actuaciones bajo supuestos de infracción de deberes jurídicos, donde el hecho generador de la responsabilidad es cualquier actuación de los órganos estatales, ejecutada con infracción de unos determinados deberes jurídicos. En un sentido normativo, el error y la arbitrariedad dejan de ser un problema de apreciación de las circunstancias de hecho que motivan una actuación o una motivación sicológicamente torcida del operador. En cambio, pasan a verificarse cada vez que se constate la infracción institucional de alguno de los deberes que tiene el Estado en su rol de juzgador y persecutor, y que son la contracara de los derechos de los ciudadanos frente a él. Estos elementos generadores dejan de tener un carácter censurador de la actuación deficiente de un operador del sistema (fiscal o juez) y pasan a tener un carácter más bien objetivo en términos de infracción de una norma, es decir, su configuración requiere solo la constatación del carácter antijurídico de la actuación.

En esta lógica interpretativa, cobran especial relevancia los controles previstos dentro del sistema de persecución penal, ya que "un sistema con reglas de reducción del error procesal mal diseñadas o con prácticas de persecución penal y de actuaciones judiciales que tiendan al error producirá muchas

\footnotetext{
21 En este sentido, se ha declarado que "en el caso de las resoluciones impugnadas a través de la solicitud de autos, es posible apreciar que todas ellas cuentan con numerosos elementos de convicción, consistentes en prueba documental y testimonial de lo que se colige que tanto la formalización, como la medida cautelar que le fuera impuesta contaban con el debido sustento en las distintas etapas procesales en que fueron dictadas, sin que pueda ser calificadas como injustificadamente erróneas por la diferente valoración que, en sentencia luego de llevarse a cabo el juicio oral, se otorgó a los medios de prueba allegados" (SCS Rol 79829-2016, Considerando Cuarto).
} 
sentencias equivocadas" (Valenzuela, 2017, p. 99), por lo que no solo el diseño de estas formas de control, sino que también cómo los operadores las ejecutan, son cuestiones radicales dentro de un sistema de persecución penal. Un modelo acusatorio que se basa en la distribución de funciones podría ofrecer unas mayores posibilidades de evitación de errores, pero no por sí solo. Para ello se requiere que esa división de funciones sea efectiva, que los operadores ejerzan adecuada y fielmente los mecanismos de fiscalización y un conjunto de estándares normativos que, partiendo de la base del estado de inocencia como regla por defecto, fijen el umbral que la prueba y su apreciación debe superar para fundar racional y legítimamente la declaración de responsabilidad y la consiguiente imposición de la pena ${ }^{22}$.

La defensa juega aquí un rol importante, tal como ya ha sido destacado por la jurisprudencia:

en un sistema procesal informado por los principios de contradicción, bilateralidad de la audiencia, y de imparcialidad del tribunal, la proactividad que echa de menos el peticionario, la ley la espera hoy del defensor del imputado [...], interviniente a quien corresponde poner al sentenciador en conocimiento de aquellos antecedentes que hagan desaconsejable o innecesaria la medida requerida o pedir otra que satisfaga las necesidades de que se trata. (SCS Rol 4.291-2014, Considerando Décimo).

Quedaría ahora por determinar cuáles son los deberes jurídicos cuya infracción verificaría un error/ arbitrariedad. En el caso del Ministerio Público, tales serían los deberes de objetividad, de unidad en la actuación, de transparencia en el contenido de la acusación, de eficiencia y eficacia, de ejercicio de la política criminal secundaria, el deber de proteger a las víctimas y testigos, el de respetar los derechos fundamentales, los derivados del carácter jerárquico del órgano (dirección y control) y el de dirección y control sobre la investigación, entre otros. En el caso de los órganos jurisdiccionales (para el error judicial), los deberes de imparcialidad, de bilateralidad, de motivación de las resoluciones, etc.

Sin pretender formular un catálogo exhaustivo, algunas situaciones de hecho contendrían infracción a deberes institucionales en el caso de las actuaciones del Ministerio Público, como las siguientes: omisión de formalización de la investigación, formalización arbitraria, solicitud infundada de medidas cautelares, omisión de solicitud de medidas cautelares personales o reales, falta de dirección y control, acusación sin fundamento, protección deficiente a víctimas y testigos, falseamiento u ocultación de antecedentes, o la indisponibilidad de información.

En un sentido normativo, una actuación errada no es aquella que da cuenta de una representación mental falsa de la realidad por parte del agente estatal actuante — como podría definirse, aplicando la definición civilista de error-, sino que puede definirse como aquella que presenta alguna de las variadas anomalías que pueden afectar a una decisión, concretadas en una serie heterogénea e innumerable de deficiencias (Mendonca, 1998, p. 202). De estas deficiencias serían relevantes para el Derecho aquellas que hayan producido en un caso concreto la lesión de un derecho fundamental, e "injustificada" aquella que sea imputable a la violación de un deber jurídico. De allí, entonces, que la voz "injustificada” pueda ser leída como "ilícita". La arbitrariedad, por su parte, consiste en la decisión institucionalizada de quebrantar los deberes jurídicos.

22 Sobre los sistemas de control, véase Navarro Dolmestch (2018, pp. 113 y ss). 


\section{Conclusiones}

La naturaleza de garantía de la responsabilidad institucional del Estado por actuaciones injustificadamente erróneas o arbitrarias del Poder Judicial o del Ministerio Público, obligan a interpretarla de forma que esta puede ser efectiva en términos de resguardar adecuadamente los derechos de las personas que se relacionan con el sistema de persecución penal.

Sobre la base de su desarrollo jurisprudencial, se puede afirmar que esta no ha logrado desplegar su rol de garantía, por cuanto ha sido objeto de una interpretación errada por parte de los tribunales, que la han aplicado conforme a los criterios configuradores de la responsabilidad civil indemnizatoria prevista en el derecho común, régimen que obedece a otros fundamentos. Esta transposición se manifiesta en que para la configuración del hecho generador de la responsabilidad institucional, los tribunales exigen indagar en aspectos fácticos del comportamiento de los agentes estatales actuantes (jueces y fiscales), relacionados con las motivaciones de estos al actuar.

Una forma de solucionar el problema consiste en la reinterpretación de los elementos configuradores de la responsabilidad institucional, sacándolos del ámbito fáctico en el que jurisprudencialmente se han desenvuelto hasta ahora, y otorgándoles un carácter normativo, como infracción de deberes institucionales. En esta perspectiva, la responsabilidad institucional no solo se genera por la actuación torcida (arbitraria) o negligente (errónea) de un juez o un fiscal, sino por el quebrantamiento de los deberes positivizados (objetividad, eficiencia, imparcialidad, de motivación, etc.), a través de actuaciones u omisiones imputables a la organización misma (como, por ejemplo, la falta de definición de criterios de persecución penal). En esta comprensión, los criterios de imputación subjetiva son reemplazados por un criterio de imputación normativa consistente en la infracción de los deberes juridificados que rigen la actuación de los órganos del sistema de persecución penal.

\section{Bibliografía citada}

Ballivian, Pedro (2013): "Responsabilidad del Estado por conductas injustificadamente erróneas o arbitrarias del Ministerio Público: análisis comparativo y jurisprudencial”, Ius et Praxis, 19, 2: pp. 53-84.

Barros, Enrique (2012): Tratado de responsabilidad extracontractual. (Santiago, Editorial Jurídica de Chile).

Bermúdez, Jorge (2002): "La responsabilidad extracontractual de la administración del Estado por falta de servicio y por el daño ambiental", Revista de Derecho de la Pontificia Universidad Católica de Valparaíso, XXIII: pp. 253-264.

Carocca Pérez, Álex (1987): "Reparación de los errores y arbitrariedades judiciales", Revista de Derecho de la Pontificia Universidad Católica de Valparaiso, 11: pp. 205-240.

Cordero, Luis (2010): La responsabilidad de la administración del Estado (Santiago, Legal Publishing).

Cordero, Luis (2012): "La responsabilidad por falta de servicio y la jurisprudencia de la Corte Suprema", en Letelier, Raúl (coordinador), La falta de servicio (Santiago, Thomson Reuters).

Corral, Hernán (2013): Lecciones de responsabilidad civil extracontractual (Santiago, Thomson Reuters).

Duce, Mauricio y Riego, Cristián (2007): Proceso penal (Santiago, Editorial Jurídica de Chile).

Enteiche, Nicolás (2011): "El fundamento de la responsabilidad extracontractual del Estado administrador en Chile: revisión de la evolución jurisprudencial (1999-2010)", Revista Actualidad Jurídica, 23: pp. 109-135. 
Fiamma, Gustavo (1989): "La acción constitucional de responsabilidad y la responsabilidad por falta de servicio", Revista chilena de derecho, 16, 2: pp. 429-440.

Garrido Montt, Mario (1999): "La indemnización por error judicial en Chile", Ius et Praxis, 5,1: pp. 473482.

Hernández, Domingo (1979): "Indemnización por error judicial", Revista de Derecho Público, 25/26: pp. 187-198.

Hernández, Domingo (1999): “Error judicial: ensayo de interpretación constitucional”, Ius et praxis, 5,1: pp. 461-472.

Martín Rebollo, Luis (1999): "Ayer y hoy de la responsabilidad patrimonial de las administración: un balance y tres reflexiones", Revista de administración pública, 150: pp. 317-366.

Mendonca, Daniel (1998): “Errores judiciales”, Cuadernos de derecho público, 4: pp. 199-206.

Navarro Dolmestch, Roberto (2018): Derecho procesal penal chileno I (Santiago, Ediciones Jurídicas de Santiago).

Pierry, Pedro (1996): "Algunos aspectos de la responsabilidad extracontractual del Estado por falta de servicio", Revista de derecho público, 59: pp. 287-309.

Pierry, Pedro (2000): "La responsabilidad extracontractual del Estado por falta de servicio", Revista de Derecho del Consejo de Defensa del Estado, 1: pp. 11-39.

Precht, Jorge (2004): “Resolución injustificadamente errónea o arbitraria’ en la indemnización por error judicial”, Estudios Constitucionales, 2, 1: pp. 175-180.

Soto Kloss, Eduardo (1983): "Responsabilidad del Estado por la actividad jurisdiccional. Notas para un enfoque unitario de la responsabilidad extracontractual del Estado", Revista Chilena de Derecho, 10, 1: pp. 45-58.

Tornos, Joaquín (1985): "La responsabilidad patrimonial del Estado por el funcionamiento de la administración de justicia. Algunos aspectos conflictivos, con especial referencia al procedimiento para hacerla efectiva”, Revista española de derecho constitucional, 13: pp. 71-122.

Valenzuela, Jonatan (2017): Hechos, pena y prcoeso. Ensayo sobre la racionalidad y prueba en el derecho procesal penal chileno (Santiago, Rubicón Editores).

Zúñiga, Francisco (2008): "La acción de inmdemnización por error judicial. Reforma constitucional. Regulación infraconstitucional y jurisprudencia”, Estudios Constitucionales, 2: pp. 15-41.

Zúñiga, Francisco (2009): "La acción de indemnización por error judicial. Reforma constitucional y regulación infraconstitucional", Anuario de Derecho Constitucional Latinoamericano, XV: pp. 189208.

\section{Normas citadas:}

Constitución Política de la República de Chile (1980).

Código Civil de la República de Chile, edición electrónica obtenida de www.leychile.cl.

Ley N 18.575 (12/11/1986) Ley Orgánica Constitucional de Bases Generales de la Administración del Estado.

Ley No 19.640 (15/10/1999) Orgánica Constitucional del Ministerio Público (LOCMP)

Ley No 18.695 (09/05/2006) Orgánica Constitucional de Municipalidades (LOCBGAE) 


\section{Jurisprudencia citada:}

Cortes de Apelaciones (Temuco), 30 de marzo de 2009, Rol N 2288-2008. Disponible en www.pjud.cl [Fecha de consulta: 10 de noviembre de 2020].

Cortes de Apelaciones (Temuco), 2 de abril de 2009, Rol N¹903-2008. Disponible en www.pjud.cl [Fecha de consulta: 10 de noviembre de 2020].

Cortes de Apelaciones (Temuco), 21 de noviembre de 2012, Rol No 560-2012-Civil. Disponible en www. pjud.cl [Fecha de consulta: 10 de noviembre de 2020].

Cortes de Apelaciones (Concepción), 17 de enero de 2014, Rol Nº 1548-2013. Disponible en www.pjud. cl [Fecha de consulta: 10 de noviembre de 2020].

Cortes de Apelaciones (Santiago), 18 de enero de 2016, Rol N 9732-2015, Disponible en www.pjud.cl [Fecha de consulta: 10 de noviembre de 2020].

Corte Suprema, 21 de enero de 2009, Rol No 5270-2008. Disponible en: https://corte-suprema-justicia. vlex.cl/vid/cueto-sandoval-juan-55547464 [Fecha de consulta: 10 de noviembre de 2020].

Corte Suprema, 19 de marzo de 2009, Rol N²640-2008. Disponible en www.pjud.cl [Fecha de consulta: 10 de noviembre de 2020]. [Fecha de consulta: 10 de noviembre de 2020].

Corte Suprema, 30 de septiembre de 2010, Rol N 398-2010. Disponible en https://corte-suprema-justicia. vlex.cl/vid/otto-albert-koch-gonzalez-436747962?_ga=2.147160503.1274595729.1605021832472629113.1605021832 [Fecha de consulta: 10 de noviembre de 2020].

Corte Suprema, 10 de mayo de 2011, Rol N 7720-2010. Disponible en: https://corte-suprema-justicia.vlex. cl/vid/juan-ricardo-garcia-rodriguez- $\quad$ 436767210?_ga=2.70546704.1274595729.1605021832472629113.1605021832 [Fecha de consulta: 10 de noviembre de 2020].

Corte Suprema, 24 de mayo de 2011, Rol N²804-2010. Disponible en: https://corte-suprema-justicia. vlex.cl/vid/mario-antonio-canala-436827974?_ga =2.150420790.1274595729.1605021832 472629113.1605021832 [Fecha de consulta: 10 de noviembre de 2020].

Corte Suprema, 6 de julio de 2011, Rol No 2762-2009. Disponible en: https://corte-suprema-justicia. vlex.cl/vid/-333063786?_ga=2.85742233.1274595729.1605021832-472629113.1605021832 [Fecha de consulta: 10 de noviembre de 2020].

CorteSuprema, 22 de septiembre de 2011, RolN ${ }^{\circ}$ 4252-2009. Disponible en: https://corte-suprema-justicia. vlex.cl/vid/-333054846?_ga=2.141434418.1274595729.1605021832-472629113.1605021832 [Fecha de consulta: 10 de noviembre de 2020].

Corte Suprema, 11 de julio de 2013, Rol N 5911-2011. Disponible en: https://corte-suprema-justicia. vlex.cl/vid/bravo-valerio-fisco-chile-473416186?_ga=2.81607959.1274595729.1605021832472629113.1605021832 [Fecha de consulta: 10 de noviembre de 2020].

Corte Suprema, 12 de julio de 2011, Rol N²765-2009. Disponible en: https://corte-suprema-justicia. vlex.cl/vid/-333063774?_ga=2.78999956.1274595729.1605021832-472629113.1605021832 [Fecha de consulta: 10 de noviembre de 2020].

Corte Suprema, 3 de diciembre de 2013, Rol $\mathrm{N}^{\circ}$ 671-2013. Disponible en: https://cortesuprema-justicia.vlex.cl/vid/pinto-lopez-francisco-consejo-defensa-482308174? $\mathrm{ga}=2.3561776 .1274595729 .1605021832-472629113.1605021832$ [Fecha de consulta: 10 de noviembre de 2020].

Corte Suprema, 28 de mayo de 2014, Rol No 14421-2013. Disponible en: https://corte-suprema-justicia.

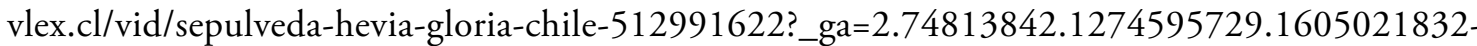
472629113.1605021832 [Fecha de consulta: 10 de noviembre de 2020]. 
CorteSuprema,12demarzode2014, RolN $4291-2014$. Disponibleen:https://corte-suprema-justicia.vlex.cl/ vid/leon-vallet-conjunto-habit-manutara-497188558?_ga=2.6050483.1274595729.1605021832472629113.1605021832 [Fecha de consulta: 10 de noviembre de 2020].

Corte Suprema, 9 de junio de 2014, Rol No 4921-2014. Disponible en: https://corte-suprema-justicia. vlex.cl/vid/fernando-flores-fortunatti-514497218?_ga=2.179212964.1274595729.1605021832472629113.1605021832 [Fecha de consulta: 10 de noviembre de 2020].

Corte Suprema, 1 de diciembre de 2014, Rol $N^{\circ}$ 22498-2014. Disponible en: https:// corte-suprema-justicia.vlex.cl/vid/alejandro-enrique-lopez-campo-546767890? $\mathrm{ga}=2.115881478 .1274595729 .1605021832-472629113.1605021832$ [Fecha de consulta: 10 de noviembre de 2020].

CorteSuprema, 26deenerode2015, Rol No 12451-2014. Disponibleen: https://corte-suprema-justicia.vlex. $\mathrm{cl} / \mathrm{vid} /$ sagredo-rodriguez-miguel-angel-554407250?_ga=2.116792582.1274595729.1605021832472629113.1605021832 [Fecha de consulta: 10 de noviembre de 2020].

Corte Suprema, 20 de abril de 2015, Rol No 22356-2014. Disponible en: https://corte-suprema-justicia. vlex.cl/vid/elias-ricardo-cartes-parra-566389294?_ga=2.82653718.1274595729.1605021832472629113.1605021832 [Fecha de consulta: 10 de noviembre de 2020].

Corte Suprema, 11 de mayo de 2015. Rol No 25685-2014. Disponible en: https://corte-suprema-justicia.

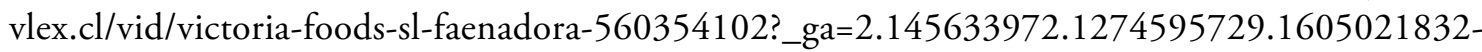
472629113.1605021832 [Fecha de consulta: 10 de noviembre de 2020].

Corte Suprema, 7 de julio de 2015, Rol № 3075-2015. Disponible en: https://corte-suprema-justicia.vlex. $\mathrm{cl} /$ vid/giovanni-natale-di-constanzo-577260578?_ga=2.187143592.1274595729.1605021832472629113.1605021832 [Fecha de consulta: 10 de noviembre de 2020].

Corte Suprema, 8 de julio de 2015, Rol N ${ }^{\circ}$ 1579-2015. Disponible en: https://corte-suprema-justicia. vlex.cl/vid/577934491?_ga=2.146174644.1274595729.1605021832-472629113.1605021832 [Fecha de consulta: 10 de noviembre de 2020].

Corte Suprema, 24 de septiembre de 2015, Rol No10668-2015. Disponible en: https://cortesuprema-justicia.vlex.cl/vid/arancibia-montenegro-guillermo-antonio-583185950? $\mathrm{ga}=2.179777956 .1274595729 .1605021832-472629113.1605021832$ [Fecha de consulta: 10 de noviembre de 2020].

Corte Suprema, 28 de septiembre de 2015, Rol No 8095-2015. Disponible en: https:// corte-suprema-justicia.vlex.cl/vid/barrales-gonzalez-oscar-fisco-583433638? $\mathrm{ga}=2.175642914 .1274595729 .1605021832-472629113.1605021832$ [Fecha de consulta: 10 de noviembre de 2020].

Corte Suprema, 30 de diciembre de 2015, Rol N²9801-2015. Disponible en www.pjud.cl [Fecha de consulta: 10 de noviembre de 2020].

CorteSuprema, 28deenerode2016, RolN ${ }^{\circ}$ 16527-2015. Disponibleen: https://corte-suprema-justicia.vlex. $\mathrm{cl} / \mathrm{vid} / \mathrm{merino}$-aravena-marcelo-fisco-592578770?_ga=2.148856119.1274595729.1605021832472629113.1605021832 [Fecha de consulta: 10 de noviembre de 2020].

Corte Suprema, 31 de mayo de 2016, Rol N 16978-2016. Disponible en: https://corte-supremajusticia.vlex.cl/vid/barriga-fisco-chile-641374461?_ga=2.70220304.1274595729.1605021832472629113.1605021832 [Fecha de consulta: 10 de noviembre de 2020].

Corte Suprema, 11 de agosto de 2016, Rol No 30956-2016. Disponible en: https://corte-suprema-justicia. vlex.cl/vid/lara-gomez-gabriel-fisco-646853425?_ga=2.83262998.1274595729.1605021832472629113.1605021832 [Fecha de consulta: 10 de noviembre de 2020]. 
CorteSuprema, 15 dediciembrede2016, Rol N52932-2016. Disponible en: https://corte-suprema-justicia.

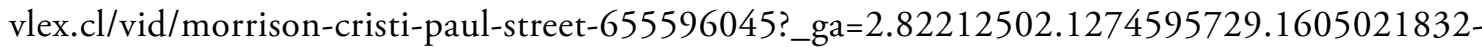
472629113.1605021832 [Fecha de consulta: 10 de noviembre de 2020].

Corte Suprema, 9 de marzo de 2017, Rol N 79829-2016. Disponible en www.pjud.cl [Fecha de consulta: 10 de noviembre de 2020].

Corte Suprema, 8 de junio de 2017, Rol No 4739-2017. Disponible en: https://corte-suprema-justicia.vlex. $\mathrm{cl} / \mathrm{vid} /$ ulloa-gonzalez-mario-eduardo-682441293?_ga=2.144645429.1274595729.1605021832472629113.1605021832 [Fecha de consulta: 10 de noviembre de 2020].

Corte Suprema, 31 de octubre de 2017, Rol No 83373-2016. Disponible en: https:// corte-suprema-justicia.vlex.cl/vid/servando-eduardo-vicente-jordan-695852573? $\mathrm{ga}=2.141907378 .1274595729 .1605021832-472629113.1605021832$ [Fecha de consulta: $10 \mathrm{de}$ noviembre de 2020].

Corte Suprema, 28 de noviembre de 2017, Rol $N^{\circ}$ 33813-2017. Disponible en: https:// corte-suprema-justicia.vlex.cl/vid/alvaro-enrique-gonzalez-opazo-697886269? $\mathrm{ga}=2.73226515 .1274595729 .1605021832-472629113.1605021832$ [Fecha de consulta: 10 de noviembre de 2020].

Corte Suprema, 5 de diciembre de 2017, Rol № 233-2017. Disponible en: https:// corte-suprema-justicia.vlex.cl/vid/bustamante-cruz-maria-angelica-699200705?_ $\mathrm{ga}=2.179262116 .1274595729 .1605021832-472629113.1605021832$ [Fecha de consulta: $10 \mathrm{de}$ noviembre de 2020].

Corte Suprema, 6 de junio de 2018, Rol N44656-2018. Disponible en: www.pjud.cl [Fecha de consulta: 10 de noviembre de 2020].

CorteSuprema, 3 de septiembre de 2018, Rol No 41934-2017. Disponible en: https://corte-suprema-justicia. vlex.cl/vid/causa-n-41934-2017-743547989?_ga=2.85758233.1274595729.1605021832472629113.1605021832 [Fecha de consulta: 10 de noviembre de 2020].

Corte Suprema, 18 de octubre de 2018, Rol N 39368-2017. Disponible en: www.pjud.cl [Fecha de consulta: 10 de noviembre de 2020].

CorteSuprema,26denoviembrede2018, RolN³8096-2017. Disponibleen:https://corte-suprema-justicia. vlex.cl/vid/causa-n-38096-2017-746609797?_ga=2.79116692.1274595729.1605021832472629113.1605021832 [Fecha de consulta: 10 de noviembre de 2020].

Corte Suprema, 19 de mayo de 2020, Rol N $\mathrm{N}^{\circ}$ 12505-2019. Disponible en: https://corte-supremajusticia.vlex.cl/vid/causa-n-12505-2019-844629065?_ga=2.2913840.1274595729.1605021832472629113.1605021832 [Fecha de consulta: 10 de noviembre de 2020].

Corte Suprema, 20 de julio de 2020, Rol No 21165-2019. Disponible en: https://corte-suprema-justicia. vlex.cl/vid/causa-n-21165-2019-846788789?_ga=2.171849248.1274595729.1605021832472629113.1605021832 [Fecha de consulta: 10 de noviembre de 2020].

Corte Suprema, 24 de agosto de 2020, Rol No 29629-2019. Disponible en: https://corte-suprema-justicia. vlex.cl/vid/causa-n-29629-2019-847410788?_ga=2.186654376.1274595729.1605021832472629113.1605021832 [Fecha de consulta: 10 de noviembre de 2020]. 
Roberto Navarro-Dolmestch 